Vol. 4, No. 2, 2018

Ihor Hrytsay $^{1}$, Vladyslav Topchij ${ }^{2}$, Andriy Kuk ${ }^{3}$

1. Department of Mechanical Engineering Technologies, Lviv Polytechnic National University, Ukraine, Lviv, S. Bandery street 12, E-mail: i.gryc@i.u

2. Department of Descriptive Geometry and Engineering Graphics, Lviv Polytechnic National University, Ukraine, Lviv, S. Bandery street 12, E-mail: Vladyslav.I.Topchii@lpnu.ua

3. Department of Mechanical Engineering Technologies, Lviv Polytechnic National University, Ukraine, Lviv, S. Bandery street 12, E-mail: Andrii.M.Kuk@lpnu.ua

\title{
COMPUTER 3D MODELLING OF CHIP GEOMETRY AND FORCE FIELD IN THE HOBBING PROCESS
}

Received: August 21, 2018 / Revised: October 31, 2018 / Accepted: December 26, 2018

(C) Hrytsay I., Topchij V., Kuk A., 2018

Abstract. Nowadays, the main method of machining the gears with a module in the range 1$25 \mathrm{~mm}$, which are integral parts of modern machines, remains hobbing. Operations of the toothed crown processing determine the efficiency of the entire technological process of manufacturing gears. Thus, the time expenses and performance, the cost of the gears, and their final quality depend to a large extent on these indicators in operations of hobbing. Considering the importance of this process for mechanical engineering, considerable attention of scientists is devoted to its modelling. Chip parameters are the key source of information required for comprehensive and complete analysis of the hobbing process. Despite the large number of publications devoted to this problem, there is still no methodology for adequate reproduction of these parameters. Known methods and models are characterized by significant simplifications and do not reproduce completely the kinematics of this complex process. This article presents a new approach to graphical modelling of the chip parameters in the hobbing process, which is based on the analysis and synthesis of elementary kinematic motions, related to unit motions and displacements of the hob cutting elements in the process of removing the metal in the gap between the teeth of the processed gear. The algorithm for forming the instantaneous transitional surface between the gear teeth and the threedimensional (3D) space geometry of the chips on all active teeth of the tool is implemented in the graphic system AutoCAD. The article presents the results of computer modelling of chips in the climb and up-cut hobbing with Archimedean and convoluted hobs. Complete information on the geometric structure of the cut layers provides the basis for complex and system modelling of this process at the level of separate racks, teeth and edge of a hob. In combination with the data on the intensity of plastic deformation, stresses and temperature obtained for the corresponding conditions of hobbing in the Deform system, data on the parameters of the cut layers create opportunities for predicting the heating and wear of cutting elements of a hob, their loading, strength of protective coatings, transient processes of the cutting force and temperature, designing of optimal technological processes of hobbing and management of these processes.

Keywords: workgear, hob, hobbing process, modelling, cutting parameters, chips geometry, force, spatial, loading, simulating.

\section{Introduction}

The gears are integral parts of modern machines, which in the near future do not have an alternative in most applications. These are parts of increased complexity and considerable laborability, which are produced in significant annual volumes in all branches of mechanical engineering.

The main method of cutting the gears with a module in the range $1-25 \mathrm{~mm}$ is hobbing with modular hobs. Operations of hobbing determine the efficiency of the entire technological process of manufacturing 


\section{Computer 3D Modelling of Chip Geometry and Force Field in the Hobbing Process}

gears. Thus, their productivity has the greatest influence on the total time of production of these parts; hobs are among the most complex and expensive cutting tools, which also require significant costs to keep them in working condition: the cost of hobbing is $50-60 \%$ of the cost of machining gears, with almost half of these costs being the cost of hobs. In addition, the precision of the production of the gears and the operational quality of the gear drives depend on the accuracy achieved in the hobbing operations.

Modern hobs are shown in Fig.1. They are highly expensive because of the increased demands on the properties of the tool material and the complexity of the design. Their cost additionally increases due to the applying of coatings and equipping with hard alloy plates.

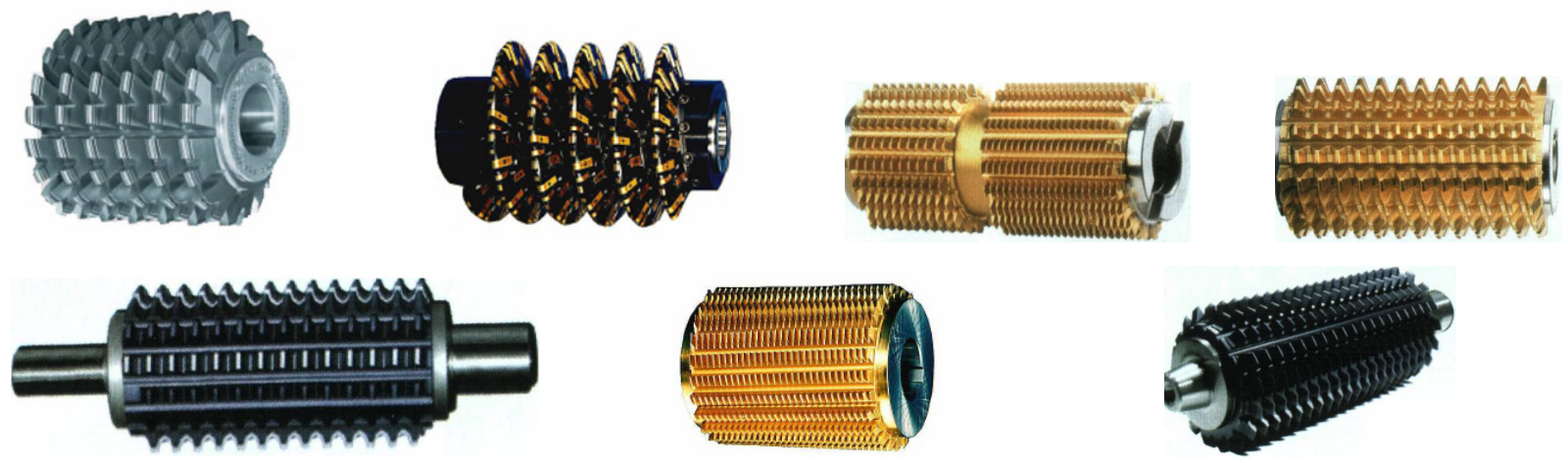

Fig. 1. Typical designs of modern hobs

The Topicality of the Issue

Widespread application of hobbing and its importance for engineering have led to increased attention to the modelling of this process, which aims to optimize cutting modes, increase process performance, maximize wear resistance of hobs and minimize cutting tool cost, reduce oscillations and vibrations in the elastic system of gear cutting machine, provide the necessary accuracy of the processing, improve the cutting scheme and the design of hobs, etc.

Chip parameters are the key source of information required for comprehensive and complete analysis of the hobbing process. The shape and size of the cut layers, their distribution between the blades, teeth and columns (tool racks) in the course of cutting characterize interrelated and interdependent static and dynamic deformation and contact processes on the teeth surfaces, as well as force and thermal phenomena during hobbing. In particular, there are the following characteristics dependent of the chip parameters:

- the cutting force and its uneven distribution for a revolution of the hob, as well as dynamic loads applied to the gear cutting machine components;

- frictional forces on the front and back surfaces of the blades and teeth;

- the work of cutting;

- the heating and the cutting temperature;

- wear of teeth, durability of the hob;

- transient processes of the cutting force and the cutting temperature, elastic deformations and vibrations of the gear cutting machine;

- the constrained cutting and its effect on the hobbing process.

However, the hobbing process is one of the most difficult of all known cutting and shaping processes. In fact, it consists of four kinematic displacements that occur simultaneously and continuously: hob rotation, its motion in an axial feed, rotation of the workpiece, and constructive motion - the displacement of hob cutting elements located on the hob helical surface along the hob axis. The complexity of the modelling of this process is that the boundaries of the surface, in which there is a cutting in one gap between the teeth, constantly change their outlines, location and shape with respect to the hob teeth. This surface is formed on the workpiece as a certain transitional surface between an unprocessed surface and a partially machined gap between the teeth of the processed gear. All the teeth which carried out cutting all 


\section{Ihor Hrytsay, Vladyslav Topchij, Andriy Kuk}

the time until some particular moment of processing, participate in its formation. Continuous change in the shape and size of the transitional surface determines the shape, size, and cross-sectional parameters of the chips cut with teeth and blades of the tool. The adequate reproduction of this surface is a basis for a correct quantitative evaluation of the chip parameters in the hobbing process.

The representation of this transitional surface is given in Fig.2 showing a partially hobbed spur gear. The hob which had passed a distance equal to the axial feed while the gear made a complete revolution, begins to cut starting a new processing cycle at the gear gap which is seen in Fig.2, a. Intermediate transitional surfaces formed by the hob teeth traces in the gear gaps, can be seen also in Fig. 2, b.

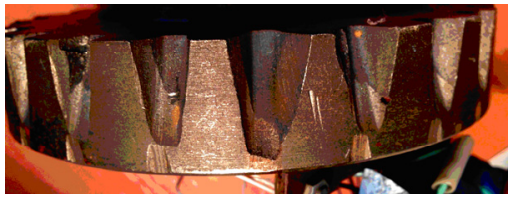

a

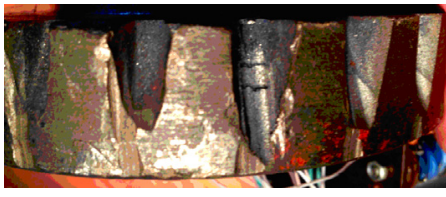

b

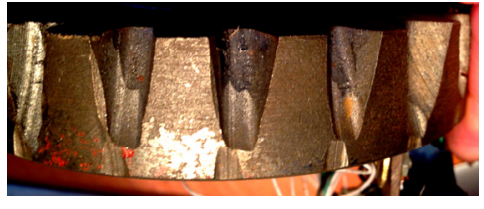

Fig.2. Shapes of the teeth gaps transitional surface

The photos above also show the cutting work of the hob teeth in different parts of the hob. The top input edges are loaded in the output section (relatively the interaxial perpendicular) as shown in Fig.2, a and b, while the work of cutting of the input edges increases in the middle section (Fig.2, c).

\section{Objectives of Research}

The goal of the article is to perform analysis and synthesis of the kinematics of the hobbing process for modelling of 3D three-dimensional (3D) geometry of a chips and cutting force.

\section{Review of Modern Information Sources}

Among the numerous scientific papers devoted to this problem, several of them can be identified, in which the method and results of modelling the chip parameters in the hobbing process on the basis of 3D graphic reproduction of cutting element traces using CAD systems [1-14] are given. In these works, on the basis of the use of the possibilities of computer engineering graphics systems, the motion of the hob helical surface during rotation about its axis, as well as the cutting surface of a certain tooth, have been described. The overlay of the splines of the hob teeth during its rotation allowed partially describing the transitional surface and outlining the shape of the chips. However, the assumptions and restrictions adopted in these works simplify the actual shape of chips, and, in the end, simplify the hob cutting scheme to the plane one. The reason for this is the excessive simplification of the cutting process performed in these works, which results in the fact that all four kinematic motions taking place in the cutting-shaping process are not taken into account. Because of such approaches, in these works, the 3D shape of the transitional surface is not reproduced, and the 3D geometry of chips cut with the hob teeth does not correspond to their actual parameters.

\section{Research Results}

1. Gear Hobbing Features. Considering the hob, we will separate the cutting process from the forming one [15]. This provision comes from the fact that although the profiling of the gears is due to the removal of the stock from the gear gaps, but the dimensions of the cut layers and the chip parameters do not affect directly the properties of the formed profiles, although this effect is observed indirectly, due to the cutting force, elastic deformations and oscillations in the system.

The hobbing process that extends over the entire length of the gear (the width of the workgear) consists of three stages: the entry, the full cut, and the hob exit (Fig.3). The entry stage (pos. A) lasts from the moment of touching the outer surface of the hob to the face surface of the gear being cut, until the axis of the hob is displaced in the motion of the axial feed below the plane of the upper face surface (in the upcut hobbing, the motion from the top - position 1), and in the climb hobbing (motion from the bottom up) - until the axis is displaced above the plane of the bottom face surface of the workpiece (position 2). The 


\section{Computer 3D Modelling of Chip Geometry and Force Field in the Hobbing Process}

next stage is the full cut, when the hob processes the gear at the full workgear width (pos. B). The stage of the full cut ends and the hob exit starts from the moment when the cutting depth is reduced and the hob axis outputs beyond the plane of the face surface of the gear (pos. C).

The chip, which is removed from the gear gap with each tooth on the hob helical surface, is limited by: a) the cutting surface, which is the same for all teeth constructed on the basis of a single initial outline; b) outside cylindrical surface of the workpiece, which depends on the position of each tooth on the active length of the hob; c) a combination of cutting surfaces of all the teeth that performed the cutting in this gear gap before this hob tooth.

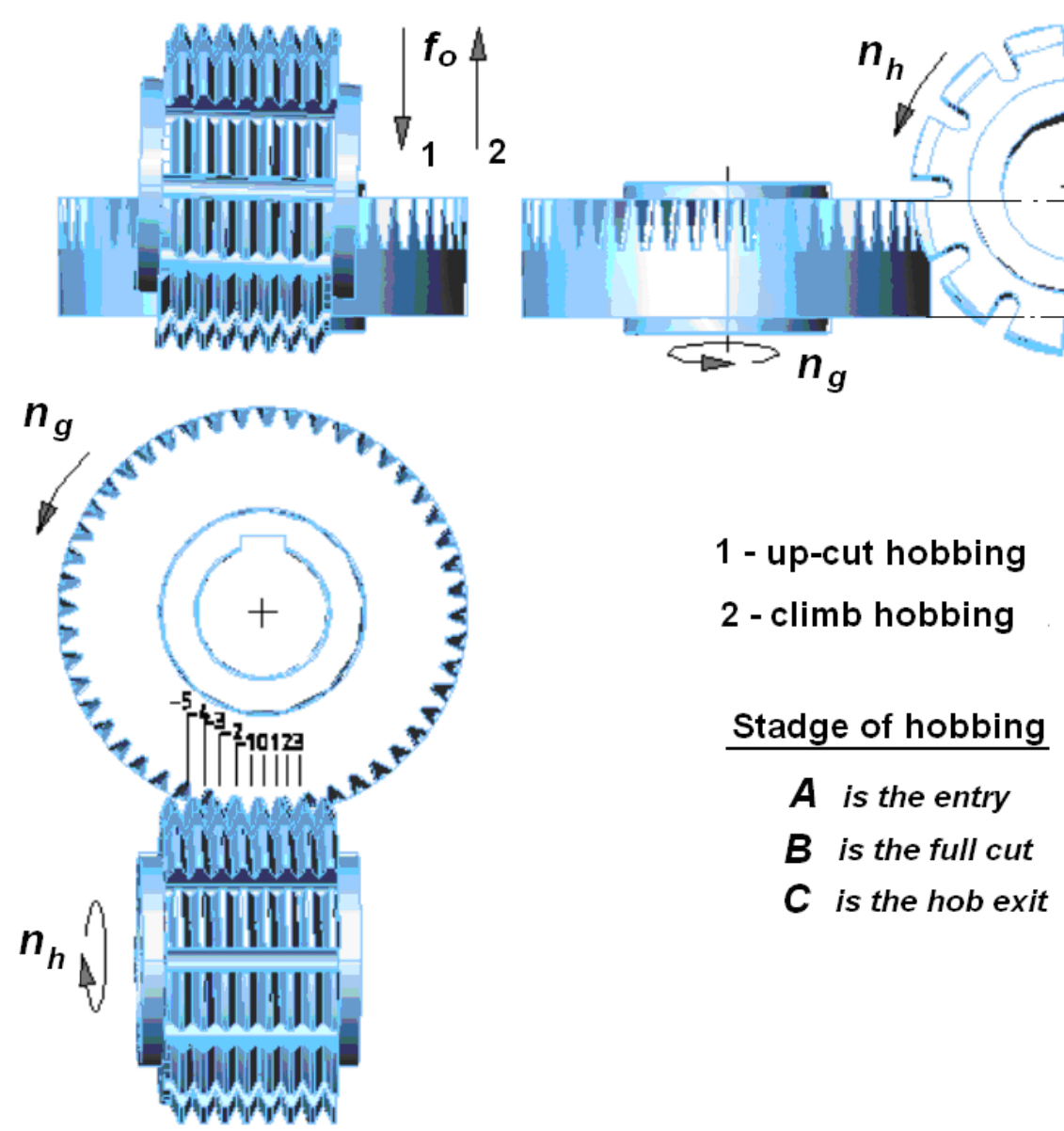

Fig. 3. Gear hobbing simulation kinematics scheme

The cutting surface of each tooth is formed by its outline - trapezoid with the slope angle of the side line, equal to the engagement angle and the profile angle of the initial outline, during the rotation of this outline about the axis of the hob - the main motion, that is, the cutting motion. Trajectory of motion of this surface - a spline, description and graphic plotting of which are not difficult; this spline is the same for all the teeth that rotate about the hob's axis.

The intersection of the spline of each tooth of the hob with the outer cylindrical surface of the workpiece can also be described both analytically and graphically using modern CAD systems.

The most difficult task in modelling the 3D geometry of chips cut with the hob teeth is to reproduce the plurality of all the cutting surfaces of the hob teeth, which had cut in each gear gap during the previous time of cutting-shaping. Outer boundaries of these surfaces, taking into account their mutual overlay and intersection, when combined with the four cinematic motions of the workpiece and tool, determine the geometric structure of the chip and shape of its cross sections which are formed by intersecting with the tooth front plane in different angular positions on the length of the cutting arc. At each moment of the full cut, the outer boundaries of the transitional surface between the formed involute tooth profile and the unprocessed surface of the workgear correspond to the inner surface of the chip. As can be seen in Fig.1, in 


\section{Ihor Hrytsay, Vladyslav Topchij, Andriy Kuk}

each gear gap during the rotation of the processed gear, the shape and dimensions of this surface and of the chips cut off stepwise with all the hob teeth, change continuously with the change of the tooth rotation angle, and are repeated periodically in the processing cycle. Within this transitional surface, each subsequent cutting cycle in one gear gap is continued after a revolution of the workpiece with the table of the gear cutting machine and the displacement of the hob by the magnitude of the axial feed.

2. Analysis of kinematics of hobbing process. From the above it follows that the determination of the outer boundaries of these surfaces, simultaneously with the determination of the spline boundaries for each hob tooth limited with the workpiece surface, is a prerequisite for the exact geometric model of the chip parameters in the hobbing.

The following provisions serve as the basis for the analysis of the regularities of modeling of the instantaneous transitional surface in an arbitrary gear gap between the teeth of a hobbed gear.

2.1. Continuous kinematic motions of cutting can be decomposed into elementary constituents. The primary elementary motion and the one that lasts for the smallest time is the turn of the hob performing the cutting motion, by one angular step:

$$
\tau=\frac{360^{0}}{Z_{h}} .
$$

During this turn the gear is rotated by the profiling angle $\psi$ :

$$
\psi=\frac{360^{0}}{Z_{n} \cdot Z_{g}},
$$

where $Z_{h}$ is the number of columns (racks) of the hob; $Z_{g}$ is the gear teeth number.

Simultaneously and for the same time, the point on the hob helical surface moves along its axis by the value of the single displacement:

$$
\Delta x=\frac{\pi \cdot m}{\mathrm{Z}_{\mathrm{h}} \cdot \cos \lambda},
$$

where $\lambda$ is helix angle of the hob; $\pi m$ is the hob's rake base pitch.

For example, by hobbing with a cutting speed of $40 \mathrm{~m} / \mathrm{min}$ of a gear having 36 teeth and a module 5 $\mathrm{mm}$, with a hob of the outside diameter $100 \mathrm{~mm}$ and having 10 racks, the rotational speed of the hob will be:

$$
n=\frac{1000 \cdot \mathrm{V}}{\pi \cdot \mathrm{D}_{\mathrm{h}}}=\frac{1000 \cdot 40}{3,14 \cdot 100}=127.4 \mathrm{~min}^{-1}
$$

the time of one revolution of the hob will be equal to $0.47 \mathrm{~s}$, and the time of turning the hob by the angular step is $0.047 \mathrm{~s}$. During this time the gear will turn in the course of the circular feed by an angle $\psi=1^{0}$, and the point located on the hob helical surface will move along the hob axis to a distance equal to $\Delta \mathrm{x}=1.57 \mathrm{~mm}$.

2.2. Taking into account the short duration of these elementary displacements, the condition is assumed that the cutting process varies discretely with a time interval equal to the time of turning the hob by one angular step, in our case, it is $47 \mathrm{~ms}$. In this condition the mutual positions of the cutting elements of the hob and of the gear are assumed to be fixed.

3. Regularities of modelling of the $3 D$ chips geometry.

3.1. Proceeding from these preconditions and starting positions, we will recreate the process of forming an involute spur gear instantaneous transitional surface for a certain hob tooth. Let us consider the kinematics of cutting a gear mentioned above parameters, axial feed $3 \mathrm{~mm} / \mathrm{rev}$. The length of the input section $L_{p}$ of the hob is:

$$
L_{p}=R_{f} \cdot \operatorname{tg} \theta,
$$

where: $\theta=\arccos \frac{R_{f}}{R_{a}} ; R_{a}$ and $R_{f}$ are the radii of the tooth tip circle and gear dedendum circle respectively: 


\section{Computer 3D Modelling of Chip Geometry and Force Field in the Hobbing Process}

$\mathrm{R}_{\mathrm{a}}=\frac{m \cdot(\mathrm{Z}+2)}{2} ; \mathrm{R}_{\mathrm{f}}=\frac{m \cdot(\mathrm{Z}-2 \cdot 1,25)}{2}$.

The number of hob teeth that may be placed on the hob helical surface of the length $L_{p}$ can be determined from the dependence:

$$
q=\frac{\mathrm{L}_{\mathrm{p}}}{\Delta \mathrm{x}}=\frac{\mathrm{L}_{\mathrm{p}}}{\pi \cdot \mathrm{m}} \cdot \mathrm{Z}_{\mathrm{h}} .
$$

The axis of symmetry of the central gap between the teeth of the hobbed gear lies in a plane passing through the gear rotation axis perpendicularly to the face surface of the gear. It is called the plane of the interaxial perpendicular. The line of the intersection of this plane with the plane of the face surface of the gear is defined as an interaxial perpendicular. The position of this gear gap is denoted by the number " 0 ", then the theoretical number of teeth on the input and output parts of the hob relative to the interaxial perpendicular will be equal to $q_{\text {in }}=q_{\text {out }}=q / 2$; the calculated active length of the hob at the input is equal to the active length at the output. In our case: $\theta=\arccos \frac{85}{96,25}=28^{0} ; L_{p}=85 \operatorname{tg} 28^{0}=45.2 \mathrm{~mm} ; 2 L_{p}=90.4$ $\mathrm{mm} ; q=28.8$, we accept $q_{\text {in }}=q_{\text {out }}=29$.

If you start numeration of teeth on the hob helical surface from the extreme one, then their sequence will be as follows: $-q_{\text {in }} ;\left(-q_{\text {in }}+1\right) ;\left(-q_{\text {in }}+2\right) ; \ldots 0 ; 1 ; 2 ; \ldots q_{\text {out }}$.

The position of any $i$-th hob tooth within the active length, that is, $q_{\text {in }}<i<q_{\text {out }}$, will be determined by the distance between this tooth and the interaxial perpendicular $L_{x}$ and by the angle $\theta_{\mathrm{i}}$ :

$$
\begin{gathered}
L_{x}=-L_{p}+i \cdot \Delta x ; \\
\theta_{i}=-\theta+i \cdot \psi .
\end{gathered}
$$

As the results of the modelling show, the actual number of teeth that perform the cutting coincides with the estimated amount only in the entry stage. In contrast, during the full cut, the active length of the hob and the number of working teeth are smaller than the estimated values, especially on the output part of the hob.

3.2. By applying the above-described approach based on the discretization of continuous kinematic motions, an algorithm for graphic modelling of the transitional surface and chip has been developed.

The gear gap, in which the $i$-th tooth performs cutting at a certain time, has been formed by all the teeth located on the hob helical surface before this position, that is, at the distance $L_{p}-L_{x}$ on the working input length of the hob; in Fig.4 the corresponding part of the tooth profile and hob are shown in red. At the same time, this gear gap has already been partially formed by the teeth that are placed ahead of this tooth on the hob helical surface. These teeth performed cutting in this gear gap in the previous position of the hob according to the axial feed. In other words, the teeth belonging to this group had partially formed the gear gap during the time preceding this. The duration of the process was equal to the period of rotation of the gear with the table of the gear cutting machine and to the time for the displacement of the hob by $s_{o}$; this part of the hob and the corresponding tooth profile are given in blue.

As noted above, in any position of the hob tooth in the working area where the cutting process is performed, the spline of this tooth is limited by the outside cylindrical surface of the workpiece and the machined surface of the gear gap. In order to construct this surface it is necessary to reproduce:

- the position of the tooth, which is located on the hob helical surface directly before this one; this tooth has already made a cut in this gear gap, with the axial feed on the tooth $f_{z}$, that is, the tooth closest to this one on the hob helical surface. The linear position of this tooth relative to the $i$-th tooth: $L_{i-1}=-L_{i}-\Delta x$, and the angular position is the rotation relative to the $i$-th tooth by angle $\psi$. Consequently, the spline of this tooth must be displaced along the hob axis by the magnitude of the unit linear displacement $\Delta x$ of the hob helical surface in the direction opposite to the displacement of the hob helical surface, and simultaneously must be rotated by the profiling angle $\psi$ in the direction of rotation of the workgear; its index is $(i-1)_{\psi}$; 


\section{Ihor Hrytsay, Vladyslav Topchij, Andriy Kuk}

- the position of the $i$-th tooth, when it cut through this gear gap in its previous position according to the axial feed of the hob: its spline must be displaced in the direction opposite to the motion of the hob with the axial feed, by the magnitude of the axial feed $f$; its index is $(i-1)$;

- preceding to this $\left((i-1)_{f}\right.$-th) tooth the one on the screw line, its spline must be displaced along the hob axis by the magnitude of the unit linear displacement $\Delta x$ of the hob helical surface in the direction of the displacement of the hob helical surface and be rotated to the angle $\psi$ opposite to the rotation of the workgear, its index is $(i-1)_{f \psi}$.

The composition, that is, the graphic overlay in the space of all four 3D splines: " $i$ ", " $(i-1)_{f}$ ", " $(i-$ $1)_{f}$ ", and " $(i-1)_{f \psi}$ " will form a 3D space outline of the chip which is cut off with the $i$-th tooth of the hob.

In Fig.5, in the form of a 2D scheme, the formation of the tooth rotation surface of a hob and the construction of the positions of this splines, which determine the 3D geometry of the chip and the spatial shape of the transitional surface, are shown.

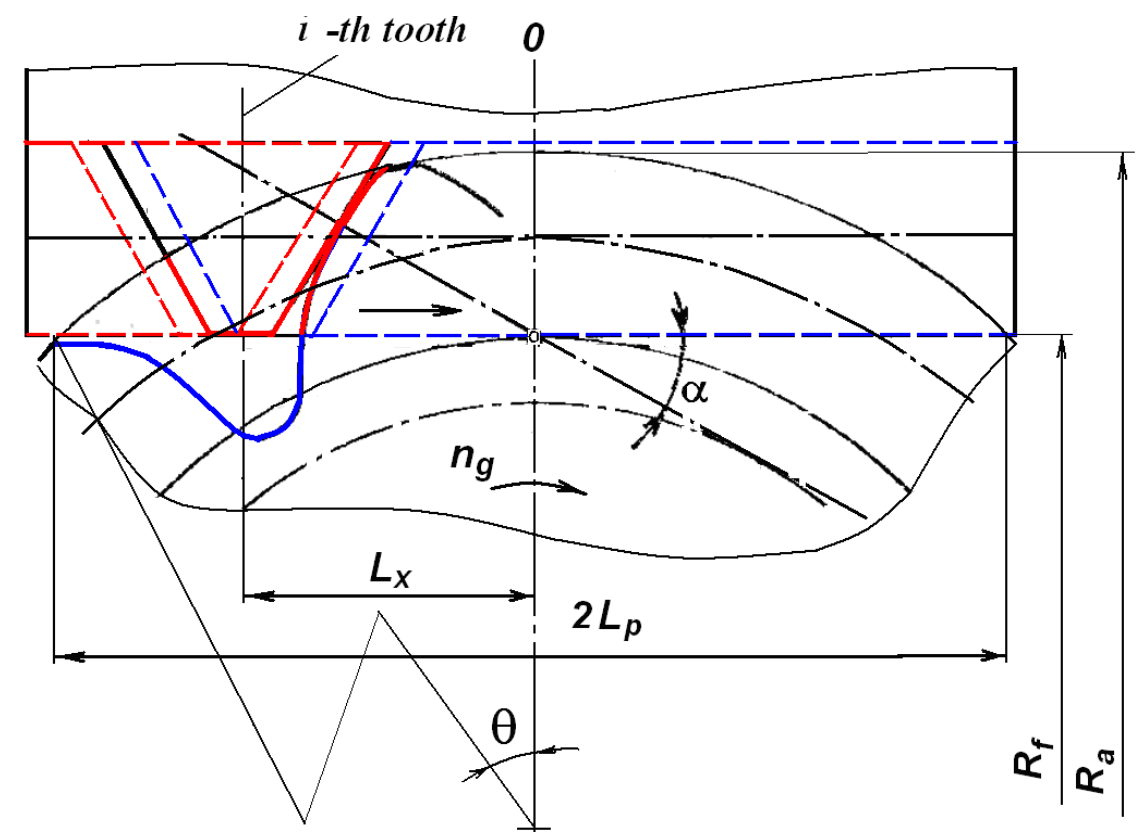

a profile of a gear tooth and the hob teeth that made the cutting in the section $L_{p}-L_{x}$ in the actual position of the hob according to the axial feed;

- a profile of a gear tooth and the hob teeth that made the cutting in the section $L_{p}-L_{x}$ in the previous position of the hob according to the axial feed

Fig. 4. The boundaries of the hob and workgear that are processed in different cutting stages

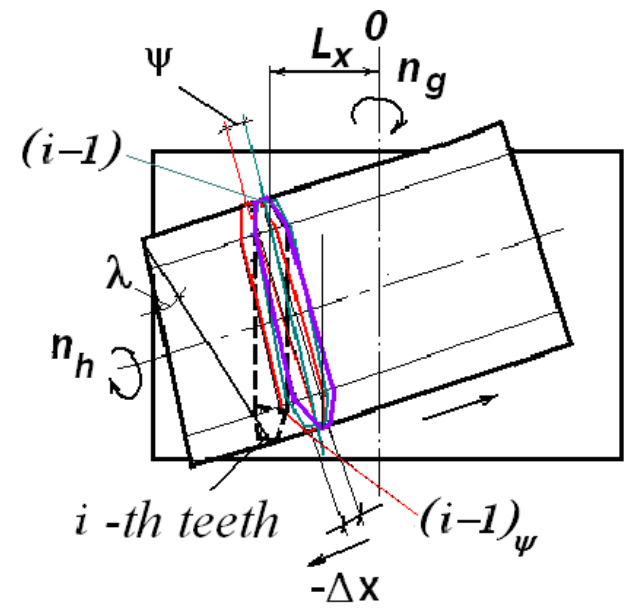

trace of rotation of the $i$-th tooth (i-th spline)

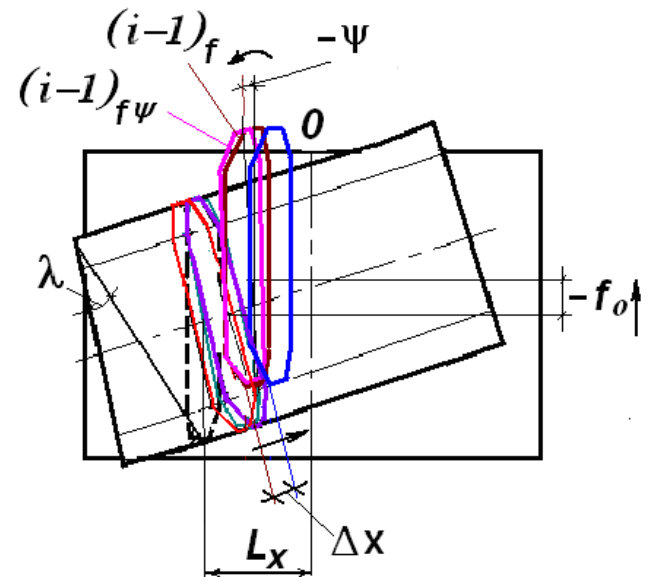

Fig. 5. Graphical representation of the algorithm for the formation of the instantaneous transitional surface of an arbitrary tooth of a hob using the positions of separate splines

Based on such algorithm, which completely takes into account the kinematics of hobbing proces, a graph-analytical model for determining the chip parameters in the hobbing process has been developed using the AutoCAD system. Fig.6a shows the spline of an arbitrary hob tooth at a certain distance from the 


\section{Computer 3D Modelling of Chip Geometry and Force Field in the Hobbing Process}

interaxial perpendicular. Figures 6, b and Fig. 6, c show the compositions of all the positions of the initial spline of this tooth, which form the transitional surface and the geometric model of the chip cut with the tooth in the up-cut and climb hobbing.

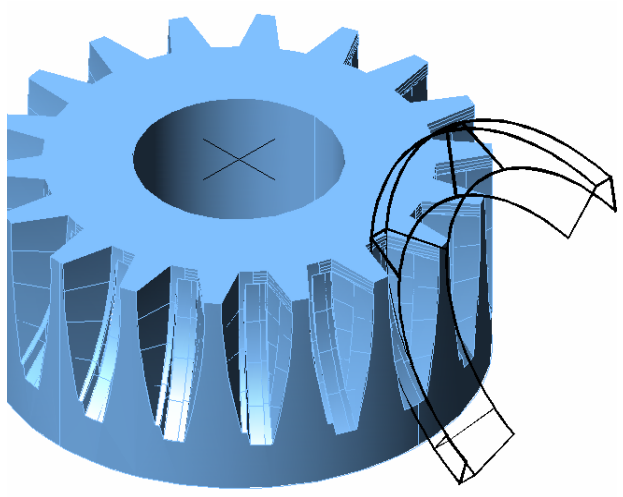

a

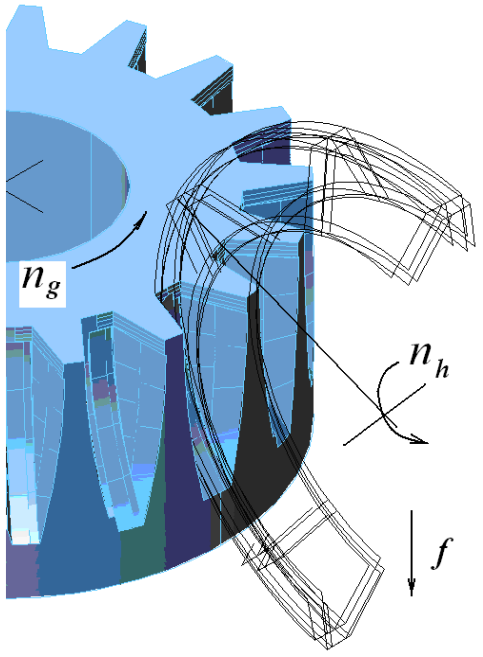

b

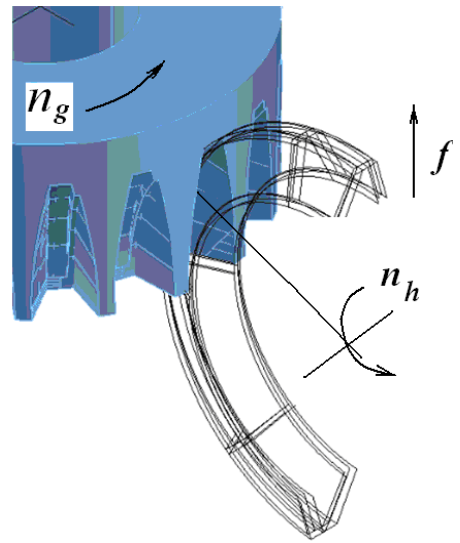

C

Fig. 6. The single spline - trace of rotation of the $i$-th tooth of the hob (a) and the composition of the splines responsible for the formation of the instantaneous transitional surface of this tooth in the up-cut (b) and climb hobbing (c)

3.3. Construction of the instantaneous transitional surface in the AutoCAD environment. In the diagram shown in Fig. 7 , the numbers $-5,-4, \ldots, 0, \ldots 3$ indicate the areas of the working zone, in which the shape of chips in the distances, multiples of $3 \Delta x$ relative to the interaxial perpendicular was determined (the negative sign corresponds to the positions on the input part of the hob). The following parameters of AutoCAD system modeling was implemented: module $m=5 \mathrm{~mm}$; outside hob diameter $D_{a h}=100 \mathrm{~mm}$, number of hob's columns $Z_{h}=10$, hob helix angle $\lambda=1^{0} 52^{\prime}$, number of hob helixes $\mathrm{k}=1$; number of gear teeth $Z_{g}=18$, gear helix angel $\beta=20^{0}$; hob setting angle $(\beta-\lambda)=18^{0} 8^{\prime}$; axial feed $f=3 \mathrm{~mm} / \mathrm{rev}$.

\begin{tabular}{|c|c|c|c|c|}
\hline $\begin{array}{c}\text { The number of the tooth of the } \\
\text { hob's helical surface relative to } \\
\text { the median plane }\end{array}$ & -20 & -16 & -12 & -8 \\
\hline View 1 & View 2
\end{tabular}

\begin{tabular}{|c|c|c|c|c|c|}
\hline $\begin{array}{c}\text { The number of the } \\
\text { tooth of the hob's } \\
\text { helical surface } \\
\text { relative to the } \\
\text { median plane }\end{array}$ & 0 & +4 & +8 & +12 & +16 \\
\hline View 1 &
\end{tabular}

Fig. 7. Chips spatial geometry in the up-cut hobbing 


\section{Ihor Hrytsay, Vladyslav Topchij, Andriy Kuk}

The results of numerical and of the graphical simulation of chips, in the up-cut hobbing process by the every fourth tooth of the hob's helical surfaces is shows in the Fig.7. 3D geometric models of chips are presented in two views.

Fig. 8, a, b, show graphs of the change in the cross-sectional area of the chips on the angles, corresponding to the maximum cut depths of the up-cut hobbing, and in Fig.8,c,d these parameters are shown for the condition of the climb hobbing (cutting conditions and parameters of the hob and gear are the same, as mentioned above). In Fig.8,a,c we can see the regularities of the change in the cross-sectional area of the chips depending on the rotation angle of the front surfaces of separate hob columns; the change in the cross-sectional area of the chips on the hob teeth depending on the hob rotation angle is shown in Fig.8,b,d (the step of teeth on the helical surface is 4).

The above methodology and the algorithm for determining the chip solid geometry and size of transitional surfaces and chips in the AutoCAD system can be used to analyze cut-off layers for other processes of cutting gears and to forming various complex surfaces that occur at continuous forming cutting of helical gears, cylindrical and conical gears with helical teeth, slot surfaces, etc.

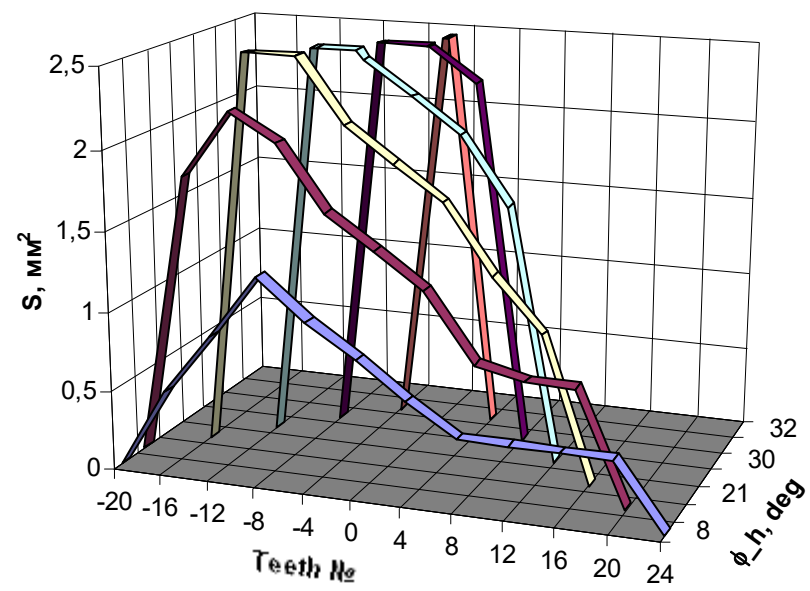

a

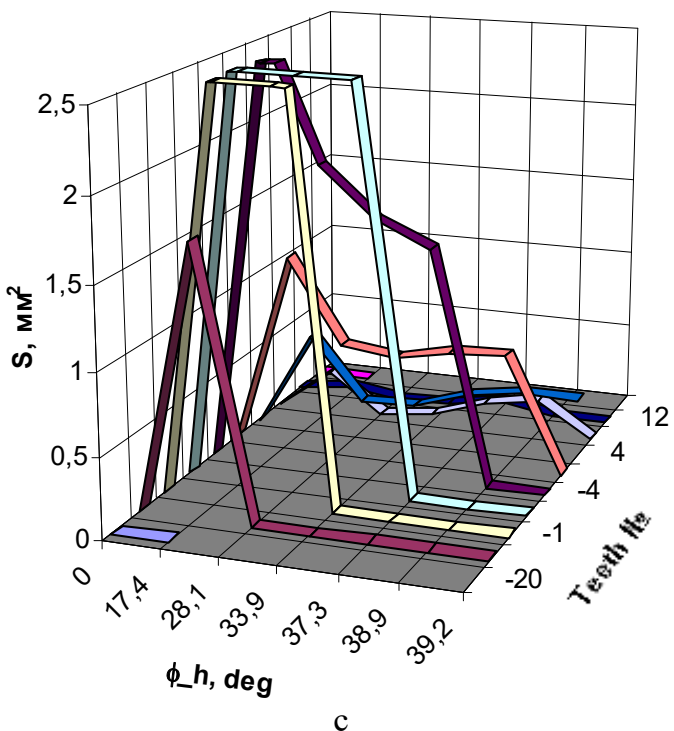

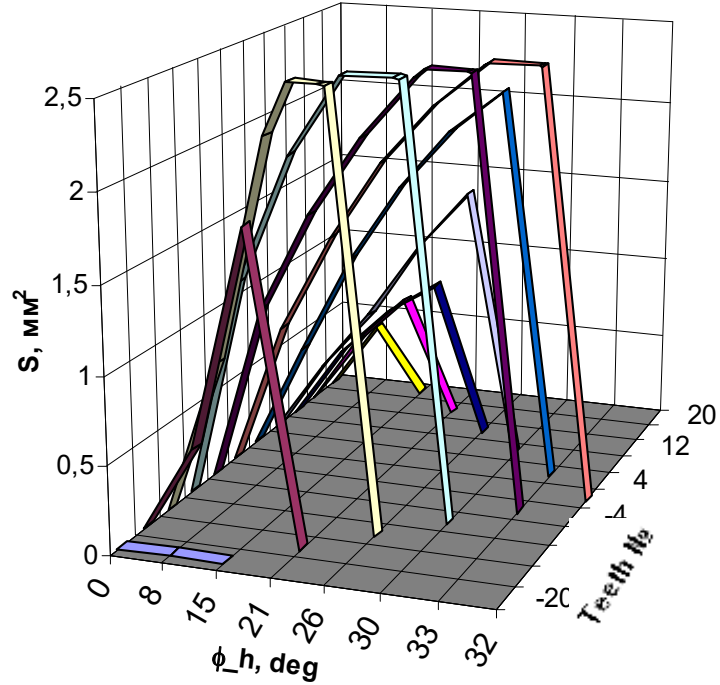

b

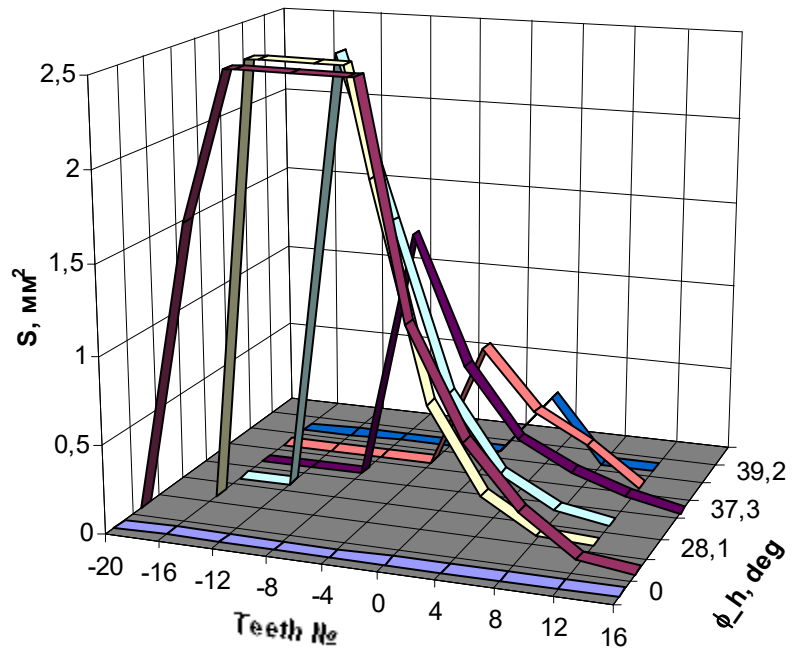

d

Fig. 8. Cross sections of the chips: $a, b$ - the up-cut hobbing; $c, d-$ the climb hobbing

4. Modeling of the cutting force and spatial loading in the hobbing process.

The results of modeling the chip parameters can be used in combination with the capabilities of the rheological modeling Deform system for cutting process. This system allows determining the shear 


\section{Computer 3D Modelling of Chip Geometry and Force Field in the Hobbing Process}

intensity, stress and temperature for the given initial conditions. This creates opportunities for complex and system modeling of the hobbing process, in particular, of spatial loading, heating and wear of the hob, transient processes of the cutting force and their effect on the occurrence of oscillations in the elastic system of the gear cutting machine, the strength of the protective coating on the hob, etc.

The hobbing cutting force is a function of the chip parameters. This occurs on the single hob tooth at the beginning of the cutting, and changes according to a some regularity, depends on the chips crosssectional area and the chips thickness. The total force acting on a separate column of the hob is equal to the geometric sum of forces acting on all the hob teeth which are simultaneously in contact with the workpiece. The unit force acting on the hob tooth, as well as the total force acting on the rack, it is a vector whose magnitude and direction during the contact with the workpiece, and corresponding elastic deformations of the components of the gear cutting machine caused by this force, are changed.

In the hobbing process the main component $P_{o}$ of the cutting force is located at the plane of hob revolution, in the direction normal to the hob axis and coincides of the cutting speed direction. Fig. 9 shows the scheme of the shear plane and the cutting force $P_{o}$.

The shear force depends on the workgear material shear stress limit [ $\tau], \mathrm{MPa}$, and the shear area $S_{\text {sh }}$ $\mathrm{mm}^{2}$ :

$$
P_{\tau}=[\tau] \cdot S_{S h}=[\tau] \cdot \frac{S}{\sin \Phi},
$$

and the force $P_{o}$ is equal to:

$$
P_{o}=P_{\tau} \cdot \cos \Phi=[\tau] \cdot S \cdot \operatorname{ctg} \Phi,
$$

where $\mathrm{S}=\mathrm{a} \cdot \mathrm{b}$ is the cross-sectional area of the chip, $a$ and $b$ are the thickness and width of the chip respectively; $\Phi$ is the shear angle:

$$
\Phi=\operatorname{arctg}\left(\frac{\cos \gamma}{\xi-\sin \gamma}\right)
$$

where $\gamma$ is the rake face angle and $\xi$ is the chip thickness ratio.

Standard hobs usually, are manufactured of a zero rake face angle, so $\xi=\operatorname{ctg} \Phi$, and the force $P_{o}$ will be equal to:

$$
P_{o}=P_{z}=\tau \cdot \xi \cdot S .
$$

The magnitude of the chip thickness ratio and the shear stress can be determined on the basis of the system Deform 2DV11 cutting process reological modeling [17-19]. For example, when cutting a hardened steel $45, \xi=1.8$, and the stress of shear deformation reaches $1.47 \mathrm{GPa}$ (Fig.10).

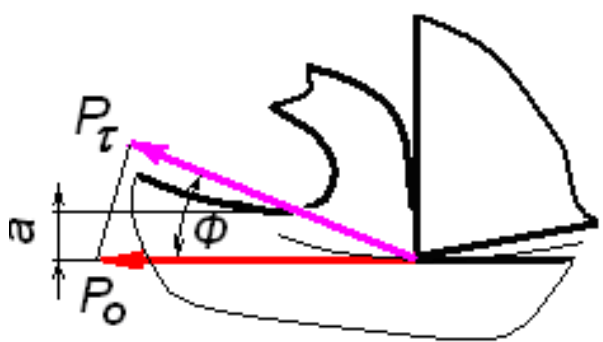

Fig. 9. The shear plane and the main component of the cutting force

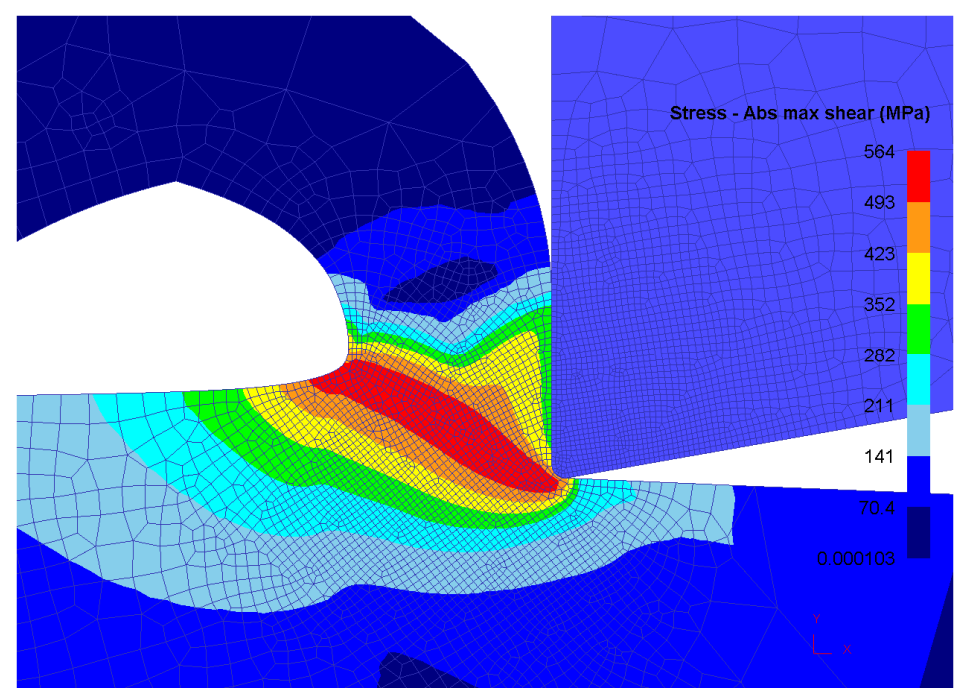

Fig.10. A plastic deformation area on the basis of rheological modeling with system Deform 2DV11 


\section{Ihor Hrytsay, Vladyslav Topchij, Andriy Kuk}

Using the equation (4), the data above and based on the 3D chip's solid geometry model, the spatial area of cutting force in a hobbing process is presented in Fig.11 (workgear material is steel 35, shear stress limit $255 \mathrm{MPa}$, chip thickness ratio is equal 1.5).

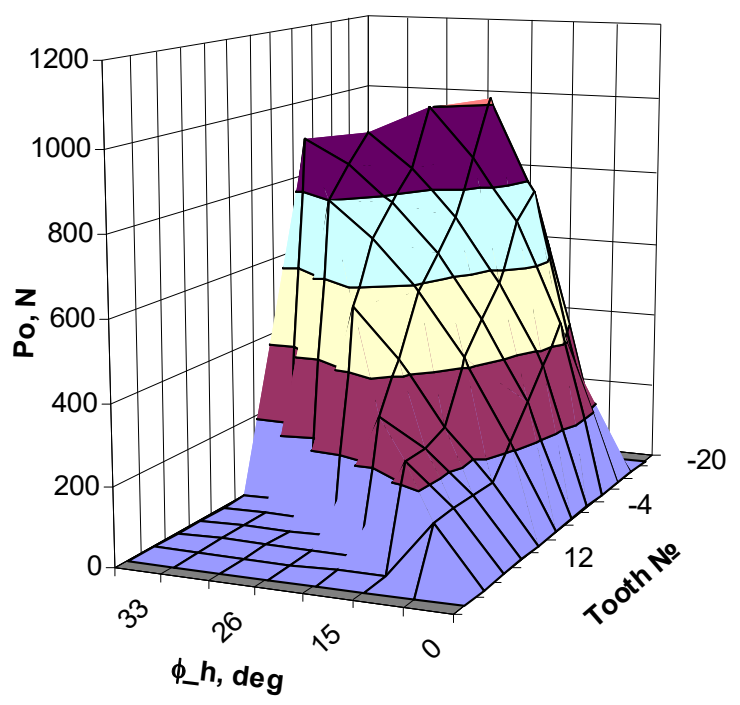

a

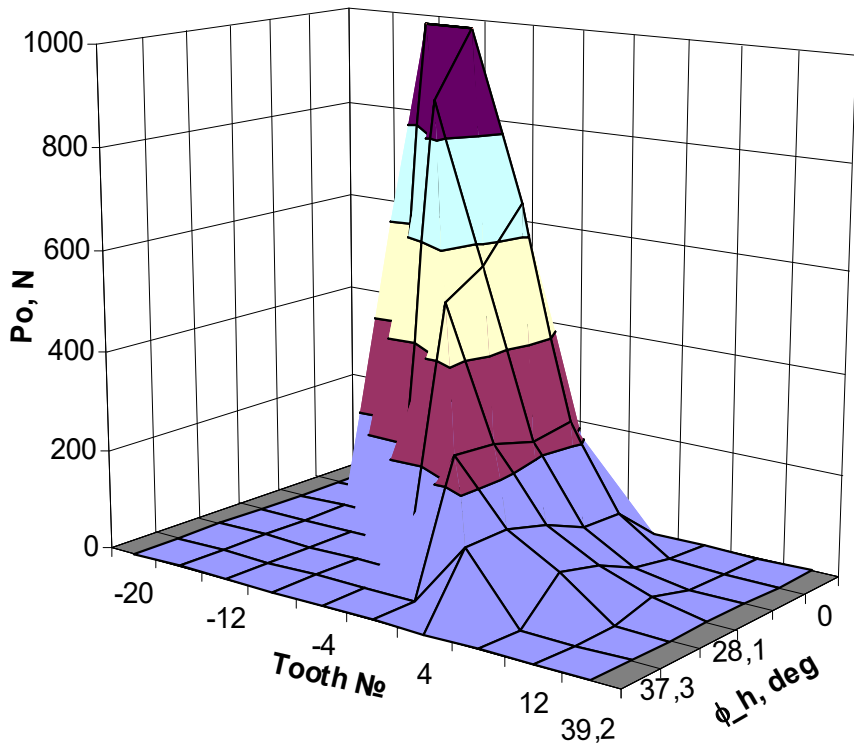

Fig.11. Spatial force load in hobbing process: $\mathrm{a}-$ the up-cut hobbing; $\mathrm{b}$ - the climb hobbing; $m=5 \mathrm{~mm} ; Z_{g}=18 ; Z_{h}$ $=10 ; D_{a h}=100 \mathrm{~mm} ; \beta=20^{0} ; \lambda=1.87^{0} ; f=3 \mathrm{~mm} / \mathrm{rev} . ;[\tau]=255 \mathrm{MPa} ; \xi=1.5$

\section{Conclusions}

The simulating method of gear hobbing and of the spatial geometry of chips based on the analysis of kinematics of hobbing process and the representation of elementary motions of cutting elements and a processed gear has been developed.

The algorithm of the 3D chip's forming has been proposed. It is based on construction of a cutting traces of the hob tooth - a splines, which reproduced in different stages of gear cutting-shaping process. The composition of the four splines for each active teeth of the hob sufficiently determines the 3D chip solid geometry with this tooth in the hob's active area.

Implementation of the created method has allowed to display in the graphical system AutoCAD 3D the geometry of chips in the process of up-cut and climb spur and helical gears hobbing and analyse the features and differences of this process, as well as identify the cutting work of each column, tooth and edge.

The obtained results of the spatial formation of chip parameters in combination with the data obtained by modelling in the Deform system on the deformation intensity of the cut layers, the temperature of the cutting surfaces, the stresses, the time of the transient processes of formation of the cutting force make it possible to comprehensively and complexly model the process of hobbing, and provide its management and optimization.

\section{References}

[1] G. Sulzer, "Leistungssteigerung bei der Zylinderradherstellung durch genaue Erfassung der Zerspankinematik" ["Increased performance in cylinder wheel production through accurate detection of the cutting edge kinematics"], PhD dissertation, Rheinisch-Westfälische Technische Hochschule Aachen, Aachen, North RhineWestphalia, Germany, 1974. [in German].

[2] P. Gutman, "Zerspankraftberechnung beim Wälzfräsen" ["Cutting force calculation during hobbing"], PhD dissertation, Rheinisch-Westfälische Technische Hochschule Aachen, Aachen, North Rhine-Westphalia, Germany, 1988. [in German].

[3] G. Venohr, "Beitrag zum Einsatz von hartmetall Werkzeugen beim Waelzfraesen" ["Contribution to the use of carbide tools during rolling"], $\mathrm{PhD}$ dissertation, Rheinisch-Westfälische Technische Hochschule Aachen, 


\section{Computer 3D Modelling of Chip Geometry and Force Field in the Hobbing Process}

Aachen, North Rhine-Westphalia, Germany, 1985. [in German].

[4] K. Joppa, "Leistungssteigerung beim Waelzfraesen mit Schnellarbeitsstahl durch Analyse, Beurteilung und Beeinflussung des Zerspanprozesses" ["Increasing the performance of rolling with high-speed steel by analyzing, assessing and influencing the cutting process"], $\mathrm{PhD}$ dissertation, Rheinisch-Westfälische Technische Hochschule Aachen, Aachen, North Rhine-Westphalia, Germany, 1977. [in German].

[5] J. Tondorf, "Erhoehung der Fertigungsgenauigkeit beim Waelzfraesen durch systematische Vermeidung von Aufbauschneiden" ["Increasing the manufacturing accuracy of the rolling process by systematically avoiding built-up edges"], PhD dissertation, Rheinisch-Westfälische Technische Hochschule Aachen, Aachen, North RhineWestphalia, Germany, 1978. [in German].

[6] A. Antoniadis, "Determination of the impact tool stresses during gear hobbing and determination of cutting forces during hobbing of hardened gears", PhD dissertation, Aristoteles University of Thessaloniki, Thessaloniki, Greece, 1988.

[7] A. Antoniadis, N. Vidakis, and N. Bilalis, "Fatigue Fracture Investigation of Cemented Carbide Tools in Gear Hobbing, Part 1: FEM Modeling of Fly Hobbing and Computational Interpretation of Experimental Results", Journal of Manufacturing Science and Engineering, vol. 124, issue 4, pp. 784-791, 2002.

[8] A. Antoniadis, N. Vidakis, and N. Bilalis, "Fatigue Fracture Investigation of Cemented Carbide Tools in Gear Hobbing, Part 2: The Effect of Cutting Parameters on the Level of Tool Stresses - A Quantitative Parametric Analysis", Journal of Manufacturing Science and Engineering, vol. 124, issue 4, pp. 792-798, 2002.

[9] V. Sinkevicius, "Simulation of gear hobbing geometrical size", Mechanika, vol. 5, no. 50, pp. 34-39, 1999.

[10] V. Sinkevicius, "Simulation of Gear Hobbing Forces", Mechanika, vol. 3, no. 28, pp. 58-63, 2001.

[11] M. Komori, M. Sumi, and A. Kubo, "Method of preventing cutting edge failure of hob due to chip crush", JSME International Journal Series C Mechanical Systems, Machine Elements and Manufacturing, vol. 47, issue 4, pp. 1140-1148, 2004.

[12] M. Komori, M. Sumi, and A. Kubo, "Simulation of hobbing for analysis of cutting edge failure due to chip crush", Gear Technology, pp. 64-69, September/October 2004.

[13] V. Dimitriou, N. Vidakis, and A Antoniadis, "Advanced Computer Aided Design Simulation of Gear Hobbing by Means of Three-Dimensional Kinematics Modeling", Journal of Manufacturing Science and Engineering, vol. 129, pp. 911-918, October 2007.

[14] K.-D. Bouzakis, S. Kombogiannis, A. Antoniadis, and N. Vidakis, "Gear Hobbing Cutting Process Simulation and Tool Wear Prediction Models", Journal of Manufacturing Science and Engineering, vol. 124, pp. 4251, February 2002.

[15] I. Ye. Hrytsay, "Modeliuvannia parametriv zriziv, syl ta momentiv pid chas narizannia zubchastykh kolis cherviachnymy frezamy" " "Simulation of the parameters of sections, forces and moments during the cutting of gear wheels with worm cutters"], Mashynoznavstvo [Mechanical Engineering], no. 7, pp. 19-23, 1998. [in Ukrainian].

[16] I. Ye. Hrytsay, V. V. Sytnik, "Sylove pole shnekovoi zuboriznoi frezy ta yoho kilkisna otsinka" ["Power field of a screw cutter mill and its quantitative estimation"], Visnyk Natsionalnoho universytetu "Lvivska politekhnika" [Bulletin of Lviv Polytechnic National University], no. 371, pp. 3-13, 1999. [in Ukrainian].

[17] V. Stupnytskyy, "Features of Functionally-Oriented Engineering Technologies in Concurrent Environment", International Journal of Engineering Research \& Technology, vol. 2, issue 9, pp. 1181-1186, September 2013.

[18] V. Stupnytskyy, "Thermodynamic pattern of the workpiece machining by the rheological imitation modelling in DEFORM-3D system", Visnyk Natsionalnoho universytetu "Lvivska politekhnika" [Bulletin of Lviv Polytechnic National University], no. 772, pp. 102-114, 2013.

[19] V. Stupnytskyy, "Computer Aided Machine-Building Technological Process Planning by the Methods of Concurrent Engineering", Europaische Fachhochschule [European Applied Sciences], vol. 2, no. 3, section 1, pp. 5053, 2013. [in Ukrainian]. 